Sowing the seeds of awareness

\section{David Streeter}

Green Inheritance.

By Anthony Huxley.

Collins-Harvill/Anchor-Doubleday:

1985. Pp. 193. £9.95, \$19.95.

Our Green and Living World: The

Wisdom to Save It.

By Edward S. Ayensu, Vernon H.

Heywood, Grenville L. Lucas and Robert A. Defilipps.

Cambridge University Press/Smithsonian Institution Press: 1984. Pp. 255. f12.95,

$\$ 24.95$.

In the Rain Forest.

By Catherine Caufield.

Heinemann/Knopf: 1985. Pp. 304.

f10.95, \$16.96.

ONE of the most striking features of current radio and television, in Britain at least, is the number of natural history programmes that are finding their way into the schedules. Radio 4 alone, for example, is currently putting out five such programmes a week. Until recently, however, wildlife was considered to consist wholly of animals; even in David Attenborough's celebrated television series Life on Earth, plants made a significant appearance in only one out of the thirteen parts.

David Bellamy's early programmes have done much to redress the balance and coincided with the emergence of a higher profile conservation movement drawing attention to, among other issues, the attrition of the tropical rain forests. The established conservation bodies began to take notice. In 1980 the Fauna Preservation Society symbolically changed its name to the Fauna and Flora Preservation Society, and in March 1984 the World Wildlife Fund and the International Union for the Conservation of Nature and Natural Resources launched an international programme for plant conservation. As part of this campaign, two books, both aimed primarily at the general market, have appeared almost simultaneously. Green Inheritance is published as the official book of the World Wildlife Fund's Plants Campaign and is written by Anthony Huxley, a well-known writer and lecturer on plants. Our Green and Living World has an appropriately international authorship of an African, two Europeans and an American.

The purpose of both books is to arouse concern over the quite staggering rate of destruction of much of the Earth's natural vegetation and to point to the consequences. Inevitably one draws comparisons between the two. As a plea for plants the case put by Anthony Huxley is the more compelling. The factual material is wellresearched, and while there are lapses here and there when the subject becomes more physiological the text as a whole provides a fascinating and lucid account of mankind's relations with and dependence upon plants. Separate chapters deal with the role of plants as food, fuel, medicine and objects of beauty, as well as with the wider role of vegetation in atmospheric and soil processes. Accounts of the origins and spread of crop plants and the medicinal uses of plants are particularly good, the latter containing some quite astonishing information such as that on the uses or, more properly, abuses of the thornapple. Apart from Huxley's persuasive style, much of the success of Green Inheritance rests with its design. The combination of a continuous discursive text alongside short illustrated vignettes providing more detailed information works well, and the standard of graphics and art work is high.

Our Green and Living World covers much the same ground and overall, perhaps, is the more authoritative of the two. However, for the general reader it is likely that its message will be less compelling, the style sometimes being closer to that of an undergraduate text. Unlike Green Inheritance it includes eight chapters on different vegetation types from deserts to rain forests and from wetlands to oceans. It is also more comprehensive on the subjects of genetic conservation and under-exploited crops (the separate chap-

\section{Who cares?}

\section{Marian Dawkins}

Strategies of Being Female: Animal

Patterns, Human Choices.

By Evelyn Shaw and Joan Darling.

Harvester/Walker: 1985. Pp. 164.

$£ 12.95, \$ 14.95$.

IT WAS only in the last few pages of this book that I understood what the authors' purpose in writing it really was. Initially, I had thought it was going to be yet another polemic about the allegedly male-dominated sexist views of sociobiology in general and its treatment of sexual behaviour in particular. As I have never been able to understand this particular criticism of sociobiology (sociobiological emphasis on the evolutionary importance of female choice seeming, if anything, to overemphasize the role of females), I began the book by being somewhat out of sympathy with the authors. Some distinctly group selectionist phraseology - such as "reproducing in anticipation of the species' future" (p.32) and "the true biological reasons for having children [are] to assure the survival of the human species" (p.121) - only increased my antipathy.

But I was curious. How were the rampaging, promiscuous, initiative-taking females they cite from all corners of the animal kingdom going to be related to our ters on firewood and cellulose are particularly good). Like Green Inheritance, the production can only be described as lavish, some of the photographs being quite superb.

The overall lesson of the two books is clear, and in particular both focus attention on the devastation of the tropical rain forests. Five years ago the US National Academy of Sciences calculated that over 50 million acres were destroyed or seriously damaged each year and the UN's Food and Agricultural Organization estimated in 1981 that at present rates almost one-fifth of the world's remaining rain forest would have gone by the end of the century. Catherine Caufield's In the Rain Forest is a carefully researched collection of essays on various aspects of rain forest ecology, exploitation and destruction. Subjects range from the building of the town and dam of Tucurui in the Amazon basin to the discovery of quinine. Figures and statistics spill off the pages, and the value of the book is enhanced by good indexing, text notes and a comprehensive bibliography, but it is not - and does not pretend to be a textbook on rain forest ecology. For anyone unfamiliar with the rain forest this is undoubtedly a good read and an intentionally perturbing one.

David Streeter is a Reader in the School of Biological Sciences, University of Sussex.

own species, as promised in the introduction? Would promiscuous female fish or birds be used as a model for human beings? Would female hyenas, with their sham male genitalia, be held up as an example to us all?

Only in the last two chapters do Shaw and Darling argue that human females are in fact different from those of any other species. Females of other species may show a wide variety of sexual behaviour, but only human females can choose which particular one they will adopt for themselves. Looking after children is not, they argue, "biologically programmed in the genes of the female". "Words - not our hormones, and not some neurological Gestalt etched into our brains - teach us how to find a mate, who is appropriate as a mate and who isn't, when to have babies, how to give birth to them, and how to take care of them" (p.152). It is all the fault of culture, and the "myth of maternalism" in particular, that women are the ones most commonly adopting a child-caring role.

It is to attack this myth of maternalism - the claim that mothers are inherently better at caring for offspring than fathers - that turns out to be the book's main purpose. Men, it is argued, are just as good at looking after children as women are, if only they are given the chance. The trouble is they are so rarely given the chance. In a wide variety of cultures, women exclude men and refuse to allow them to be present at the birth of their own children. Shaw and 
Darling argue that if only men could be present at the birth, they too would form strong bonds with their children and take on the care-taking role usually associated with mothers.

In support of this idea, they cite male wild-dogs, male marmosets and other species in which males take an active part in looking after the young. They also quote Rosenblatt's finding that male rats will

IMAGE
UNAVAILABLE
FOR
COPYRIGHT
REASONS

Mother love - black-faced vervet monkey with infant.

begin to lick and retrieve young after they have been exposed to them for several days. The male's tendency to care for young is latent and revealed only if given the opportunity: "And just like a father rat, the human father is denied access to the environmental cues that would turn on his 'maternal' behaviour'" (p.148).

There may or may not turn out to be something in all this. It is an interesting hypothesis, one which is certainly worth thinking about. What is disturbing to me is the way it is put over. Perhaps this is simply because the book is written in a popular style. Maybe words such as "babes" and "critters" have to be used to make sure readers do not feel overwhelmed by technical jargon; maybe a case has to be overstated in order to attract a public who would be bored by too much weighing up of evidence. But do we have to swing from male sexism to an equally unattractive female sexism? If we accept that women may wish and be able to fulfil a wider variety of roles than they often do, do we have to see society purely in terms of womens' choices and womens' destinies?

Shaw and Darling emphasize that "female" does not have to mean passive, meek or monogamous. But at the same time, perhaps unintentionally, they make female wishes and female roles dominant, without explaining why this kind of sexism is any more convincing - or any more acceptable - than the male kind.

Marian Dawkins is Fellow in Biological Sciences at Somerville College, University of Oxford.

\section{Ways to get back to the track}

\section{David Pimentel}

State of the World 1985: A Worldwatch Institute Report on Progress Toward a Sustainable Society.

Project director Lester R. Brown. W.W. Norton: 1985. Pp.301. Hbk $\$ 22.75, £ 18.95 ; p b k \$ 9.50, £ 7.95$.

IN PUBLISHING this detailed analysis of "the state of the world", the Worldwatch Institute has performed a valuable service for the public, government and industry. Examined in it are the interdependence of human population, global environment and world economy. Specifically, the authors assess the effect of population growth on deforestation, overgrazing, soil erosion, atmospheric pollution, and water and energy shortages. With this as a basis, they go on to consider the influence of natural resource degradation and resource shortages on the economy and standard of living of society.

Early in the book Brown and his colleagues tackle the question of whether climate change in some regions of the Earth may be population induced. They suggest that, indirectly, population growth may reduce rainfall because of overgrazing and other activities that remove or reduce vegetation cover. The increased exposure of bare soil increases the albedo: "Where this happens, as on the fringes of the Sahara, the affected areas reflect more heat into space". Canadian meteorologist, Kenneth Hare, who has investigated desertification in Africa, is quoted as concluding that "we seem to have arrived at a critical moment in the history of mankind's relation to climate. For the first time we may be on the threshold of man-induced climatic change". If indeed water shortages are population induced, then the decline can be reversed in some regions only by massive programmes in family planning, tree planting, soil and water conservation, and ecological-agricultural development on a huge scale.

The authors acknowledge the fact that major efforts to produce more food per hectare of land have slowed the growth of hunger, noting that agriculturalists have made use of biological diversity to breed new crop varieties that are more efficient in converting water and fertilizers into grain and other foods. At the same time, farmers have increased the amount of land cultivated and have greatly expanded the use of irrigation and fertilizers. Irrigation, for instance, has grown nearly three-fold since 1950 and fertilizer usage about ninefold during much the same period. All these strategies have increased crop yields.

It remains to be seen, however, how far agricultural technology can go in producing more food from the world's limited arable land resources. We already know that there are certain physical and chemical constraints on the capacity of plants to capture and fix solar energy into biomass. Recognizing such limitations, the authors question whether biotechnology will make the major changes necessary to continue improving yields. A major concern to emerge here is the effect that the rapid loss of biological diversity will have on the success of biotechnology and genetic engineering, but in placing emphasis on this point the authors neglect to explain that most species in nature are vital to the normal functioning of the ecosystem. For example, agriculture cannot function successfully with only its crop and livestock species; many organisms, especially the small organisms (such as microbes and insects) are also essential. Thus on a hectare of good land with ample water, the small organisms outweigh human biomass by at least 200 times and carry out the vital tasks of degrading wastes and chemical pollutants, and of recycling other resources.

In a chapter on energy efficiency, William Chandler reports on the important role that fossil energy plays in producing food, purifying water, protecting us from numerous kinds of diseases and transporting resources from one region to another. Several sound arguments support the view that conservation of energy and improved energy efficiency are necessary for economic improvement in both developing and developed countries. But although fossil energy is essential to our present standard of living, almost everyone agrees that new sources of energy are needed, preferably renewable in form. However, the chapter entitled "Harnessing Renewable Energy" is rather disappointing. Several of the sources cited lack scientific credibility. For example, one paper quoted here reports that producing ethanol from corn grain provides a net energy return. This is not so; in fact, the net energy loss is about 30 per cent greater than the ethanol energy produced.

Also highlighted is the idea of shifting from the corn-soybean crop mix now typical in the mid-west of the United States to a corn-sugar-beet mix. This proposed plan, which is supposed to supply all food needs for livestock plus up to 700 million barrels of ethanol, has numerous technological and agricultural flaws and has been

\section{Conservation in Britain}

In association with the publisher Webb \& Bower, and sponsored by Gulf Oil, the Conservation Foundation have published The Conservation Review, their third annual report for "everyone concerned with preserving our heritage and natural environment".

The Review is intended to increase public awareness of environmental issues and draw attention to the activities of various organizations, local, national and international. Among the contributors are David Bellamy, Patrick Jenkin, Tony Soper and Jean Medawar. Price is hbk £10.95, pbk $£ 4.95$. 